\title{
DOSES DE URÉIA NO CRESCIMENTO DE PORTA-ENXERTOS DE CITROS PRODUZIDOS EM RECIPIENTES ${ }^{1}$
}

\author{
MARLON DUTRA DEGLI ESPOSTI² \& DALMO LOPES DE SIQUEIRA ${ }^{3}$
}

\begin{abstract}
RESUMO - Este trabalho teve como objetivo, determinar a influência de doses de nitrogênio, aplicadas em cobertura na forma de uréia, no crescimento de diferentes porta-enxertos de citros, cultivados em recipientes. O experimento constou de um esquema fatorial $(2 \times 5)+(2 \times 5)$, num delineamento em

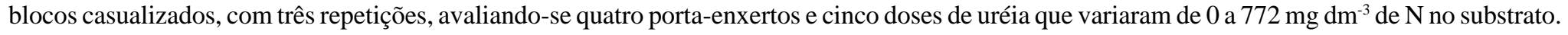
Foram avaliadas características como o número de folhas, a área foliar, a massa da matéria fresca e a seca de folha, de caule e de raízes. As espécies de porta-enxertos estudadas mostraram diferenças em relação às características de crescimento avaliadas. Os limoeiros apresentaram, durante o período de condução do experimento, as maiores alturas e diâmetro do caule, chegando mais rapidamente ao ponto de enxertia, pelo que foram considerados mais vigorosos que as tangerineiras nesse sistema de cultivo. Os limoeiros tiveram menores exigências de $\mathrm{N}$ que as tangerineiras. As doses de $\mathrm{N}$ (mg $\mathrm{dm}^{-3} \mathrm{de}$ substrato) correspondentes às maiores alturas foram 453 para o limoeiro 'Cravo', 431 para o 'Volkameriano', 624 para a tangerineira 'Cleópatra' e 610 para a 'Sunki'. O maior diâmetro foi alcançado com as doses de 455; 433; 543 e 546, respectivamente, para os limoeiros 'Cravo' e 'Volkameriano' e tangerineiras 'Cleópatra' e 'Sunki'.
\end{abstract}

Termos para indexação: adubação, uréia, Citrus, produção de mudas

\section{NITROGEN FERTILIZATION ON GROWTH OF CITRUS ROOTSTOCKS PRODUCED IN CONTAINERS}

ABSTRACT - The objective of this study was to determinate urea dose to be applied on citrus rootstocks, and evaluation of the rootstock growths in containers. The factorial scheme $(2 \times 5)+(2 \times 5)$ in a experimental design of randomized blocks was used with three replications, to evaluate four rootstocks, and five urea doses varying from 0 to $772 \mathrm{mg} \mathrm{dm}^{-3}$ in substrate. The following characteristics were evaluated: leaves number, leaf area, weight of the leaf fresh and dry matter, stem weight, and roots weights. Some differences occurred among the studied rootstock species in relation to the appraised growth characteristics. The rootstocks 'Cravo' and 'Volkameriano' showed the largest heights and stem diameters, reaching first the grafting point, therefore were considered more vigorous than both mandarin trees in this cropping system. The rootstocks 'Cravo' and 'Volkameriano' demanded less amount of $\mathrm{N}$ than the mandarin trees, since the $\mathrm{N}$ doses ( $\mathrm{mg} \mathrm{dm}^{-3}$ substrate) providing the highest height were 453 to lemon trees ' Cravo', 431 to 'Volkameriano', 624 to mandarin tree 'Cleópatra', and 610 to mandarin tree' Sunki'. The largest diameter was reached with doses of 455 , 433, 543 and 546 to the lemon trees 'Cravo' and 'Volkameriano' and the mandarin plants 'Cleópatra' and 'Sunki'.

Index terms: fertilization, urea, recipients, Citrus, production of Citrus seedling

\section{INTRODUÇÃO}

Na implantação de um pomar cítrico, vários fatores devem ser observados, principalmente a qualidade da muda, por se constituir em fator limitante. Para que uma muda cítrica tenha qualidade e atenda às exigências estabelecidas pelos órgãos certificadores, é necessário que ela seja vigorosa, tenha sanidade e apresente um sistema radicular com boa formação, sendo necessário que se conheça a origem das sementes dos porta-enxertos como também a das borbulhas a serem utilizadas no momento da enxertia.

O processo tradicional de produção de mudas cítricas consiste em se utilizar sementeiras de solo ao ar livre e a repicagem das plântulas para viveiro de campo, onde são feitas a enxertia e a formação da muda. Sistemas modernos conduzem à produção destas mudas em recipientes e em ambiente protegido, proporcionando a obtenção de plantas com bom sistema radicular, com significativa economia de tempo. A produção de porta-enxertos, quando feita em recipientes dentro de estufas ou telados e sobre mesas ou suportes, proporciona maior proteção contra CVC, gomose e nematóides, além de permitir um maior controle de ácaros (Lima, 1986; Tecnologia, 2001).

Para a produção de mudas de citros em recipientes que, na maioria das vezes, não ultrapassam o volume de $4 \mathrm{dm}^{3}$, é necessária a utilização de substratos com boas características físicas e químicas, o que, na prática, não se obtém com grande facilidade, exigindo, portanto, uma suplementação com fertilizantes que atendam às necessidades nutricionais das plantas.

Pesquisas realizadas com diferentes porta-enxertos de citros mostram que o nitrogênio é um dos nutrientes mais importantes para o crescimento vegetativo de mudas de citros (Carvalho, 1994; Decarlos Neto, 1999) e que estas apresentam uma exigência nutricional de nitrogênio diferenciada (Maust e Williamson, 1994). Decarlos Neto et al. (2002) observaram um efeito positivo da aplicação de nitrogênio no substrato de cultivo, sobre o crescimento dos porta-enxertos 'Tangelo Orlando', limoeiros 'Cravo' e 'Volkameriano' e tangerineiras 'Cleópatra' e 'Sunki', sendo as doses de 1.110; $1.240 ;, 1.410 ; 1.100 \mathrm{e} 1.140 \mathrm{mg} \mathrm{dm}^{-3} \mathrm{de}$ $\mathrm{N}$ responsáveis pelo máximo crescimento em altura destes porta-enxertos, respectivamente.

Portanto, foram objetivos desse trabalho determinar as doses de nitrogênio na forma de uréia a serem recomendadas para aplicação em cobertura de diferentes porta-enxertos de citros crescidos em citrovasos.

\section{MATERIAL E MÉTODOS}

O experimento foi realizado durante o período de março de 1998 a março de 1999 e conduzido em casa de vegetação, localizada na Universidade Federal de Viçosa (UFV).

Foram utilizadas plantas dos porta-enxertos Citrus limonia (L.) Osbeck, cv 'Cravo' (Cra); C. volkameriana Ten. e Pasq., cv 'Volkameriano' (Vol); C. reshni hort. ex Tan., cv 'Cleópatra' (Cle); $C$. sunki hort. ex Tan., cv 'Sunki' (Sun). Essas plantas foram obtidas a partir de sementes de frutos maduros, as quais foram armazenadas em câmara fria a $5^{\circ} \mathrm{C}$, até a semeadura. Em janeiro, as sementes foram semeadas a uma profundidade de $2 \mathrm{~cm}$, em bandejas plásticas contendo vermiculita expandida. Quando as plantas apresentavam $5 \mathrm{~cm}$ de altura, estas foram transplantadas para citrovasos rígidos (recipientes cilíndricos com base superior de $14 \mathrm{~cm}$ e inferior de $11 \mathrm{~cm}$ de diâmetro, com $31 \mathrm{~cm}$ de altura, perfurações na base inferior e estrias nas laterais) com capacidade para $3,8 \mathrm{dm}^{3}$ de substrato. Os citrovasos foram colocados em bancadas de madeira a $1 \mathrm{~m}$ de altura do solo, em casa de vegetação. Foi utilizado um substrato comercial à base de casca de Pinus que, na análise química,

\footnotetext{
${ }^{1}$ (Trabalho 145/2003). Recebido: 08/10/2003. Aceito para publicação: 13/04/2004.

2 Eng. Agrôn. (MSs.) Prof. Faculdade de Ciência da Saúde (FAESA), Rodovia Serafim Derenzi, 3.115, São Pedro, Vitória-ES. CEP: 29048-450, E-mail: mesposti@bol.com.br. Tel: (27)3331-4500.

${ }^{3}$ Eng. Agrôn. (DSc.) Prof. Universidade Federal de Viçosa (UFV), Rua Ph Holfs, s/n, Centro, Viçosa-MG. CEP: 365700-000, E-mail: siqueira@ mail.ufv.br. Tel: (31)38991349.
} 

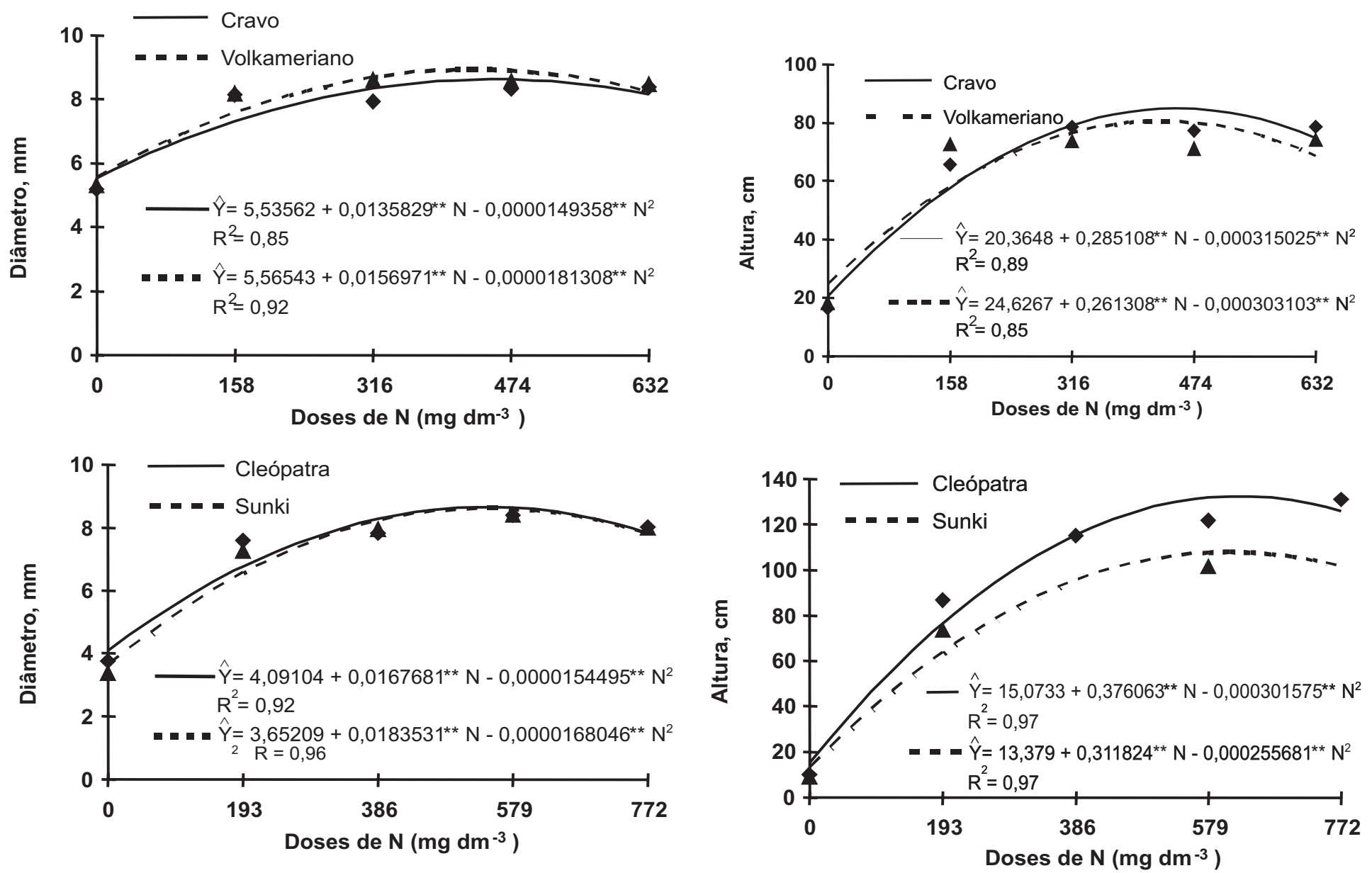

FIGURA 1 - Efeito das doses de nitrogênio adicionadas no substrato, no crescimento dos porta-enxertos, aos 305 dias após a semeadura.

apresentou as seguintes características: $\mathrm{pH}$ em $\mathrm{H}_{2} \mathrm{O}(1: 2,5)=5,9 ; \mathrm{P}=702$ $\mathrm{mg} \mathrm{kg}{ }^{-1}$ e K $=250 \mathrm{mg} \mathrm{kg}^{-1}$ (extrator Mehlich 1 ); $\mathrm{Ca}=43 \mathrm{mmol} \mathrm{kg}{ }^{-1}, \mathrm{Mg}=$ $10 \mathrm{mmol}_{\mathrm{c}} \mathrm{kg}^{-1} \mathrm{e} \mathrm{Al}=1 \mathrm{mmol}_{\mathrm{c}} \mathrm{kg}^{-1}$ (extrator $\left.\mathrm{KCl} 1 \mathrm{~mol} \mathrm{~L}^{-1}\right) ; \stackrel{\mathrm{H}}{\mathrm{H}}+\mathrm{Al}=51$ $\mathrm{mmol}_{\mathrm{c}} \mathrm{kg}^{-1}$ [extrator $\mathrm{Ca}(\mathrm{OAc})_{2} 0,5 \mathrm{~mol} \mathrm{~L}^{-1} \mathrm{pH} \mathrm{7,0];} \mathrm{SB}=60 \mathrm{mmol}_{\mathrm{c}} \mathrm{kg}^{-1}$, CTC pH7 $=172 \mathrm{mmol}_{\mathrm{c}} \mathrm{kg}^{-1}, \mathrm{~V}=54 \%$ e $\mathrm{m}=1,6 \%$.

O experimento constou de um fatorial $(2 \times 5)+(2 \times 5)$, utilizando delineamento em blocos casualizados, com três repetições. $\mathrm{O}$ primeiro fator foi constituído por quatro variedades de porta-enxertos: 'Cravo', 'Volkameriano', 'Cleópatra' e 'Sunki', e o segundo, por cinco doses de nitrogênio: 0; 158; 316; 474 e $632 \mathrm{mg} \mathrm{dm}^{-3}$ de $\mathrm{N}$ para os limoeiros e 0; 193;

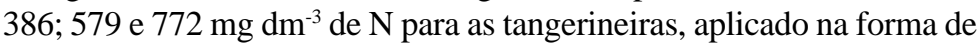
uréia. A utilização de doses de nitrogênio superiores para as tangerineiras foi em decorrência de deficiências de nitrogênio observadas no decorrer do experimento. Aunidade experimental foi composta de quatro citrovasos com uma planta cada. Adose total de N, correspondente a cada tratamento, foi dividida em 20 aplicações em cobertura, a cada 15 dias, sendo a primeira realizada sete dias após o transplantio. $\mathrm{O}$ adubo foi dissolvido em água e aplicado diretamente no substrato, sendo que cada vaso recebeu $10 \mathrm{~mL}$ de solução por aplicação. Foram realizadas irrigações diárias, com a utilização de uma mangueira, evitando-se excesso de água para que não houvesse a lixiviação do nitrogênio aplicado. Após o início das adubações com uréia, foram avaliados, a cada 15 dias, a altura $(\mathrm{cm})$ e o diâmetro $(\mathrm{mm})$ dos porta-enxertos. O diâmetro do caule foi medido a $5 \mathrm{~cm}$ a partir do colo e a altura, partindo-se do colo até a gema apical.

Aos 305 dias após a semeadura, os porta-enxertos foram cortados na região do colo, em razão de os mesmos apresentarem um diâmetro do caule ideal para a enxertia $(7,0 \mathrm{~mm}$ a $5 \mathrm{~cm}$ de altura), sendo em seguida realizadas a contagem do número de folhas, as medições da área foliar, a massa da matéria fresca e seca de folha, de caule e de raízes. Os dados obtidos foram submetidos à análise de variância, utilizando-se do nível de significância de 5\%, pelo teste F. Foram estabelecidos contrastes ortogonais que analisaram as diferenças entre os limoeiros e as tangerineiras [(Cra+Vol) vs. (Cle+Sun)]; entre os limoeiros $[(\mathrm{Cra}) v s$. (Vol)] e tangerineiras [(Cle) vs. (Sun)], sendo estes contrastes testados pelo teste de 't', ao nível de $5 \%$ de probabilidade. Os efeitos da variável quantitativa (doses de $\mathrm{N}$ ) foram submetidos ao ajuste de equações de regressão, sendo que a significância dos coeficientes de regressão das equações ajustadas foram testadas pelo teste de $\mathrm{F}$, calculado e corrigido conforme Alvarez V. (1985).

\section{RESULTADOS E DISCUSSÃO}

\section{Efeitos das doses de $\mathbf{N}$ sobre as características de crescimento} dos porta-enxertos

Houve efeito significativo $(\mathrm{P}<0,01)$ para a interação das variedades de porta-enxertos com as doses de nitrogênio aplicadas, para número de folhas, área foliar, massa da matéria seca de folha, massa da matéria seca de caule, massa da matéria seca de raiz, altura e diâmetro.

Observa-se, na Figura 1, que, com o aumento das doses de N aplicadas no substrato de cultivo, ocorreram aumentos da altura e diâmetro dos diferentes porta-enxertos, até um ponto de máximo, sendo que, a partir deste ponto, não foram mais observados aumentos da altura e diâmetro dos diferentes porta-enxertos estudados. Este comportamento pode ter ocorrido devido à diminuição do $\mathrm{pH}$ do substrato, em função da liberação de $\mathrm{H}^{+}$produzido, durante o processo de nitrificação da uréia aplicada (Decarlos Neto et al., 2002).

Na Tabela 1, estão apresentadas as doses de $\mathrm{N}$ que, aplicadas no substrato de cultivo, proporcionaram os máximos incrementos nas características de crescimento dos porta-enxertos limoeiros 'Cravo' e 'Volkameriano' e tangerineiras 'Cleópatra' e 'Sunki'. O limoeiro 'Volkameriano' precisou de menores doses de nitrogênio que o limoeiro 'Cravo' para alcançar os máximos incrementos das características de crescimento (Tabela 1). As doses de 431 e $433 \mathrm{mg} \mathrm{dm}^{-3} \mathrm{de} \mathrm{N}$, aplicadas no substrato de cultivo, proporcionaram o máximo crescimento do limoeiro 'Volkameriano' com valores de 80,9 cm de altura e 8,9 mm de diâmetro do caule, enquanto, para o limoeiro 'Cravo', os valores foram de $84,8 \mathrm{~cm}$ de altura e 8,6 mm de diâmetro do caule, respectivamente, com as doses de $453 \mathrm{e} 455 \mathrm{mg} \mathrm{dm}^{-3} \mathrm{de} \mathrm{N}$ no substrato. Com relação às duas tangerineiras, a 'Sunki' precisou de menores doses de nitrogênio que a 'Cleópatra' para alcançar os máximos incrementos na maioria das características de crescimento avaliadas, com exceção da massa da matéria seca de raiz e diâmetro do caule (Tabela 1). As doses de 610 e $546 \mathrm{mg} \mathrm{dm}^{-3} \mathrm{de} \mathrm{N}$, 
TABELA 1 - Doses de $\mathrm{N}$ aplicadas no substrato que proporcionaram o valor máximo para as características de crescimento dos diferentes portaenxertos, aos 305 dias após a semeadura

\begin{tabular}{lcccccc}
\hline \multirow{2}{*}{ Porta-enxertos } & \multicolumn{6}{c}{ Características de crescimento } \\
\cline { 2 - 7 } & NF & AF & MMSF & MMSC & MMSR & ALT \\
\hline \multirow{2}{*}{ Cravo } & 505 & -----11 & 616 & 574 & 443 & 453 \\
Volkameriano & 493 & 503 & 548 & 471 & 407 & 431 \\
Cleópatra & 670 & 772 & 772 & 772 & 589 & 624 \\
Sunki & 578 & 684 & 772 & 665 & 601 & 610 \\
\hline
\end{tabular}

${ }^{1 / N u ́ m e r o ~ d e ~ f o l h a s ~(N F), ~ a ́ r e a ~ f o l i a r ~(A F), ~ m a s s a ~ d a ~ m a t e ́ r i a ~ s e c a ~ d e ~ f o l h a ~(M M S F), ~ m a s s a ~ d a ~ m a t e ́ r i a ~ s e c a ~ d e ~ c a u l e ~(M M S C), ~ m a s s a ~ d a ~ m a t e ́ r i a ~ s e c a ~ d e ~ r a i z ~(M M S R), ~}$ altura (ALT) e diâmetro (DIAM).

aplicadas no substrato de cultivo, proporcionaram o máximo crescimento da tangerineira 'Sunki' com valores de $108,4 \mathrm{~cm}$ de altura e $8,6 \mathrm{~mm}$ de diâmetro do caule, enquanto, para a tangerineira 'Cleópatra', os valores foram de $132,3 \mathrm{~cm}$ de altura e $8,6 \mathrm{~mm}$ de diâmetro do caule, respectivamente com as doses de 624 e $543 \mathrm{mg} \mathrm{dm}^{-3}$ de $\mathrm{N}$ no substrato (Tabela 1). Os limoeiros necessitavam de menores doses de $\mathrm{N}$ para alcançar os máximos incrementos das características de crescimento avaliadas em relação às duas tangerineiras. As respostas diferenciadas entre as espécies, quando submetidas às adubações, estão relacionadas com as características genéticas que influenciam na capacidade de utilização de luz e $\mathrm{CO}_{2}$, afetando a absorção, o transporte e a interação dos nutrientes dentro da planta (Wallace et al., 1952, Gallo et al., 1960 e Bockman et al.,1990; citados por Carvalho, 1994),

\section{Características de crescimento dos porta-enxertos}

Foram observadas diferenças entre as espécies de portaenxertos estudadas, em relação às características de crescimento avaliadas, conforme os resultados dos contrastes testados (Tabela 2). Os limoeiros 'Cravo' e 'Volkameriano' apresentaram o número de folhas inferior $(\mathrm{P}<0,01)$ quando comparados juntamente com o das tangerineiras 'Cleópatra' e 'Sunki'. O número de folhas do limoeiro 'Cravo' não diferiu do valor encontrado no limoeiro 'Volkameriano', sendo observado o mesmo comportamento nas duas tangerineiras. A maior área foliar foi de $771,9 \mathrm{~cm}^{2}$ e a menor, de $523,5 \mathrm{~cm}^{2}$, respectivamente, para o limoeiro 'Volkameriano' e a tangerineira 'Cleópatra'. Resultados semelhantes foram observados por Decarlos Neto (1999) trabalhando com os mesmos portaenxertos adubados com doses crescentes de nitrogênio até a fase de repicagem, onde o mesmo encontrou maior valor de área foliar para o limoeiro 'Volkameriano' e menor para a tangerineira ‘Cleópatra. Mesmo tendo apresentado um menor número de folhas em relação à tangerineira 'Cleópatra', como observado na Tabela 2, o limoeiro 'Volkameriano' exibiu a maior área foliar total dos porta-enxertos estudados, indicando que este porta-enxerto apresenta uma área foliar média superior e morfologicamente diferente da tangerineira 'Cleópatra'.

Pela análise dos contrates (Tabela 2), verificou-se diferença significativa $(\mathrm{P}<0,01)$ entre os limoeiros e as tangerineiras, entre o limoeiro 'Cravo' e o limoeiro 'Volkameriano' e entre a tangerineira 'Cleópatra' e a tangerineira 'Sunki' com relação à área foliar. Esses resultados são corroborados pelas observações relatadas por Decarlos Neto (1999), diferindo apenas quando foram comparados os dois limoeiros isoladamente, visto que estes não diferiram quanto a essa característica.

A maior massa da matéria seca de folha foi de 7,8 $\mathrm{g} \mathrm{planta}^{-1} \mathrm{e} o$ menor de 6,2 $\mathrm{g}$ planta $^{-1}$, para as tangerineiras 'Sunki' e 'Cleópatra', respectivamente. Grassi Filho et al. (1999), trabalhando com diferentes substratos para produção de limoeiro 'Cravo' em sacos plásticos, encontraram o valor médio da massa da matéria seca de folha de 20,6 g planta $^{-1}$ no momento da enxertia. Provavelmente a discordância de resultados possa ser explicada em função de as condições de cultivo serem bastante diferentes das utilizadas nesse experimento, o que é evidenciado ainda mais pela massa da matéria seca de folha de $6,4 \mathrm{~g}$ planta $^{-1}$ apresentada pelo limoeiro 'Cravo' (Tabela 2).

Os limoeiros 'Cravo' e 'Volkameriano', quando comparados com as tangerineiras 'Cleópatra' e 'Sunki', não apresentaram diferenças significativas quanto à produção de massa da matéria seca de folhas. $\mathrm{O}$ mesmo comportamento foi verificado quando se compararam as produções dos limoeiros 'Cravo' e 'Volkameriano'. As tangerineiras, por sua vez, apresentaram diferença significativa $(\mathrm{P}<0,01)$ quanto a essa característica (Tabela 2). A maior massa da matéria seca de caule foi de $9,5 \mathrm{~g} \mathrm{planta}^{-1} \mathrm{e} o$ menor, de 6,4 $\mathrm{g} \mathrm{planta}^{-1}$, respectivamente, para a tangerineira 'Cleópatra' e o limoeiro 'Cravo'. Esses valores estão abaixo do valor médio de $11,8 \mathrm{~g}$ planta $^{-1}$ de massa da matéria seca de caule encontrado por Grassi Filho et al. (1999) para o limoeiro 'Cravo', no momento da enxertia. Analisando os resultados dos contrastes, com relação à produção da massa da matéria seca de caule, pôde-se verificar que houve diferença significativa $(\mathrm{P}<0,01)$ entre os limoeiros 'Cravo' e 'Volkameriano' quando comparados com as tangerineiras 'Cleópatra' e 'Sunki', e entre os limoeiros e as tangerineiras quando se compararam esses porta-enxertos entre si. A maior massa da matéria seca de raiz foi de $15,1 \mathrm{~g}$ planta $^{-1}$ e o menor de $10,7 \mathrm{~g} \mathrm{planta}^{-1}$, respectivamente para a tangerineira 'Sunki' e o limoeiro 'Cravo'. Esses valores estão acima do valor médio encontrado por Grassi Filho et al. (1999) para o limoeiro 'Cravo', que foi de 6,6 $\mathrm{g} \mathrm{planta}^{-1}$ de massa da matéria seca de raiz no momento da enxertia. Possivelmente, essa discordância de resultados deva-se às diferenças nas condições experimentais, principalmente com relação ao volume e às características físicas dos substratos empregados, que influenciam diretamente no desenvolvimento do sistema radicular das plantas. Analisando-se os resultados dos contrastes com relação à produção de massa da matéria seca de raiz, observou-se que os limoeiros apresentaram valores inferiores $(\mathrm{P}<0,01)$ quando comparados com as tangerineiras 'Cleópatra' e 'Sunki'. O limoeiro 'Cravo' não diferiu significativamente do limoeiro 'Volkameriano' com relação a essa característica, sendo o mesmo observado nas duas tangerineiras. Os resultados descordam em parte dos encontrados por Decarlos Neto (1999), pois esse autor observou que os limoeiros apresentaram valores superiores de massa da matéria seca de raiz quando

TABELA 2 - Valores médios das características de crescimento(1) dos porta-enxertos ‘Cravo', 'Volkameriano', ‘Cleópatra' e 'Sunki’, aos 305 dias após a semeadura

\begin{tabular}{|c|c|c|c|c|c|}
\hline \multirow[b]{2}{*}{ Porta-enxertos } & \multicolumn{5}{|c|}{ 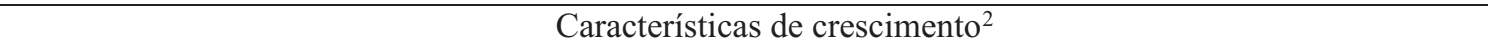 } \\
\hline & $\mathrm{NF}$ & $\overline{\mathrm{AF}}$ & MMSF & MMSC & MMSR \\
\hline & ----folhas----- & ------- $\mathrm{cm}^{2}------$ & & --g plant & --- \\
\hline Cravo & 29,6 & 620,5 & 6,4 & 6,4 & 10,7 \\
\hline Volkameriano & 29,3 & 771,9 & 6,8 & 7,9 & 11,0 \\
\hline Cleópatra & 38,9 & 523,5 & 6,2 & 9,5 & 14,6 \\
\hline Sunki & 40,5 & 734,7 & 7,8 & 7,8 & 15,1 \\
\hline
\end{tabular}

(1) Correspondentes à Média das doses de nitrogênio.

Os contrastes foram testados pelo teste de 't', a $5 \%$ de probabilidade.

(2) Número de folhas (NF), área foliar (AF), massa da matéria seca de folha (MMSF), massa da matéria seca de caule (MMSC) e massa da matéria seca de raiz (MMSR). 

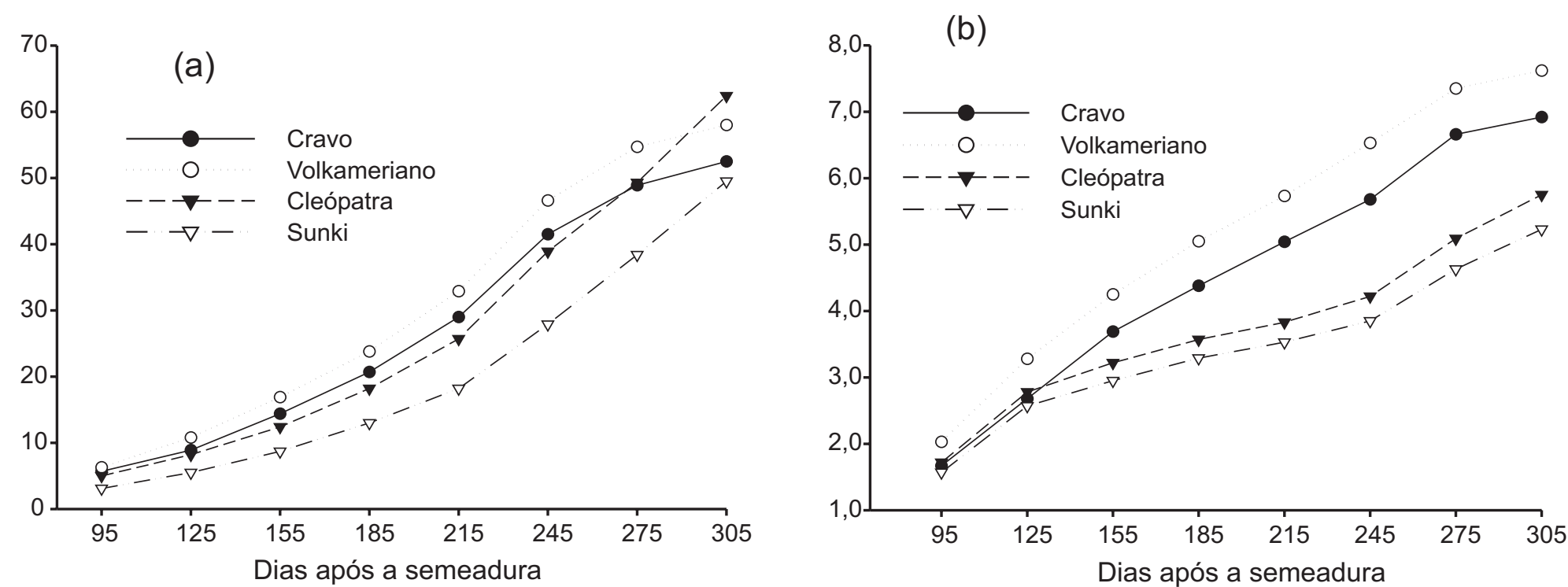

FIGURA 2 - Altura e diâmetro dos diferentes porta-enxertos, correspondente à média das doses de nitrogênio aplicadas no substrato de cultivo, nas diferentes épocas de avaliação.

comparados com as duas tangerineiras. Cabe ressaltar que esse autor trabalhou com os mesmos porta-enxertos, adubados com doses crescentes de nitrogênio, diferindo apenas no tempo de condução do experimento, pois o estudo foi finalizado quando os porta-enxertos estavam aptos a ser transplantados no campo (aos 120 dias após a semeadura).

Os limoeiros 'Cravo' e 'Volkameriano' apresentaram maiores alturas até os 180 dias após o transplantio, sendo o limoeiro 'Cravo' superado aos 210 e o limoeiro 'Volkameriano' aos 240 dias após o trasplantio pela tangerineira 'Cleópatra' (Figura 2a). Esse resultado pode ser explicado pela característica de alongamento do caule dessa espécie, sem muito ganho de diâmetro (Fontanezzi, 1989). Os porta-enxertos, ao final do experimento ( 240 dias), apresentavam alturas aproximadas de 52,5; 58,0; 62,4; e 49,5 cm, respectivamente, nos limoeiros 'Cravo' e 'Volkameriano' e nas tangerineiras 'Cleópatra' e 'Sunki'. A altura média dos porta-enxertos $(55,6 \mathrm{~cm})$ está abaixo dos valores encontrados por Grassi Filho et al. (1999), que obtiveram o valor médio de $71,20 \mathrm{~cm}$ para o limoeiro 'Cravo' no momento da enxertia.

Os limoeiros 'Cravo' e 'Volkameriano' apresentaram, durante todas as avaliações, os maiores diâmetros do caule, em relação às tangerineiras 'Cleópatra' e 'Sunki', chegando dessa forma mais precocemente ao ponto de enxertia (Figura $2 \mathrm{~b}$ ). $\mathrm{O}$ diâmetro, para atingir o ponto de enxertia $(7,0 \mathrm{~mm})$, a uma altura de $5 \mathrm{~cm}$ do colo, foi alcançado pelo limoeiro 'Volkameriano' aos 263 dias após a semeadura. Os demais porta-enxertos não alcançaram o diâmetro de enxertia antes do término do experimento (305 dias). Resultados encontrados por Fortes (1991) e Rezende (1991) revelam que o limoeiro 'Cravo' necessita de 195 a 265 dias após a semeadura para alcançar um diâmetro do caule de $5 \mathrm{~mm}$ a 15 cm de altura do colo; logo, no presente experimento, o limoeiro 'Cravo' apresentou um tempo de 215 dias para alcançar o diâmetro do caule de 5 $\mathrm{mm}$, estando dentro do intervalo encontrado na literatura.

A princípio, esperava-se que o tempo para a produção dos porta-enxertos fosse menor, visto que estes foram cultivados em condições favoráveis de umidade e sanidade e com adubação adequada para seus ótimos crescimento e desenvolvimento. Um fator que pode ter limitado a obtenção dos porta-enxertos em menor tempo foi a luminosidade da casa de vegetação, pois esta se apresentava instalada em local onde chegavam poucos raios solares durante o dia e, ainda, era coberta com placas de vidro, que diminuíram a transmissividade da radiação solar para o interior da mesma, prejudicando dessa forma $o$ crescimento e o desenvolvimento dos porta-enxertos.

\section{CONCLUSÕES}

1) Os limoeiros alcançaram o ponto de enxertia em menor tempo, e mostraram um vigor maior nesse sistema de cultivo, mesmo em relação às tangerineiras que apresentaram valores superiores para a maioria dos parâmetros de crescimento avaliados.
2) A tangerineira 'Cleópatra' mostrou maior altura e menor diâmetro do caule.

3) As doses de nitrogênio, na forma de uréia, recomendadas para cultivo dos porta-enxertos 'Cravo', 'Volkameriano', 'Cleópatra' e 'Sunki', foram, em $\mathrm{mg} \mathrm{dm}^{-3}$ de substrato, de 455; 433; 543 e 546, respectivamente, que resultaram em maior crescimento em diâmetro.

\section{REFERÊNCIAS BIBLIOGRÁFICAS}

ALVAREZ V., V.H. Avaliação da fertilidade do solo. Viçosa: UFV , 1985. 75p.

CARVALHO, S.A . Manejo da adubação nitrogenada na produção de porta-enxertos cítricos em bandejas. 1994. 74f. Dissertação (Doutorado em Fitotecnia) - Universidade Federal de Lavras, Lavras -MG., 1994.

DECARLOS NETO, A. Adubação e nutrição nitrogenada de portaenxertos de citros, semeados em tubetes. 1999. 131f. Dissertação (Mestrado em Fitotecnia) - Universidade Federal de Viçosa, Viçosa -MG., 1999.

DECARLOS NETO, A.; SIQUEIRA, D. L.; PEREIRA, P. R. G.; ALVAREZ V., V. H. Crescimento de porta-enxertos de citros produzidos em tubetes e influenciados por doses de N. Revista Brasileira de Fruticultura, Jaboticabal, v.24, n.1, p.199-203, 2002.

FONTANEZZI, G.B.S. Efeitos de micorriza vesículo-arbuscular e do superfosfato simples no crescimento e nutrição de porta-enxertos de citros. 1989. 105f. Dissertação (Mestrado em Fitotecnia) Universidade Federal de Lavras, Lavras - MG., 1989.

FORTES, L.A. Processos de produção do porta-enxerto limoeiro (Citrus limonia Osbeck cv 'Cravo') em vaso. 1991. 96f. Dissertação (Mestrado em Fitotecnia) - Universidade Federal de Lavras, Lavras -MG., 1991.

GRASSI FILHO, H.; PEREIRA, M.A.A.; SAVINO, A.A.; RODRIGUES, V.T. Crescimento de mudas de limoeiro 'Cravo' (Citrus limonia Osbeck) em diferentes substratos. Revista Brasileira de Fruticultura, Jaboticabal, v.21, n.1, p.186-190, 1999.

LIMA, J.E.O. Novas técnicas de produção de mudas cítricas. Laranja, Cordeirópolis, v.2, n.1, p.463-468, 1986.

MAUST, B.E.; WILLIAMSON, J.G. Nitrogen nutrition of containerized citrus nursery plants. Journal of the American Society for Horticultural Science, Alexandria, v.119, n.1, p.195-201, 1994.

REZENDE, L.P. Efeito do volume de substrato e do superfosfato simples na formação de porta-enxertos de citros. 1991. 97f. Dissertação (Mestrado em Fitotecnia) - Universidade Federal de Lavras, Lavras -MG., 1991.

TECNOLOGIA mostra eficácia. Revista do Fundecitrus, Araraquara, v.14, n.105, p.8-11, 2001. 